\title{
The heterogeneity of prostate cancers lacking AR activity will require diverse treatment approaches
}

\author{
Mark P Labrecque ${ }^{1}$, Joshi J Alumkal2, Ilsa M Coleman³, Peter S Nelson ${ }^{3,4,5}$ and Colm Morrissey \\ 1Department of Urology, University of Washington School of Medicine, Seattle, Washington, USA \\ 2Department of Internal Medicine, Rogel Cancer Center, University of Michigan, Ann Arbor, Michigan, USA \\ 3Division of Human Biology, Fred Hutchinson Cancer Research Center, Seattle, Washington, USA \\ ${ }^{4}$ Division of Public Health Sciences, Fred Hutchinson Cancer Research Center, Seattle, Washington, USA \\ ${ }^{5}$ Department of Medicine, University of Washington School of Medicine, Seattle, Washington, USA
}

\section{Correspondence should be addressed to C Morrissey: cmorriss@uw.edu}

This paper is part of a thematic review section celebrating 80 Years of Androgen Deprivation as a Treatment for Prostate Cancer. The guest editors for this section were Amina Zoubeidi and Paramita Ghosh.

\begin{abstract}
The use of androgen deprivation therapy and second-line anti-androgens in prostate cancer has led to the emergence of tumors employing multiple androgen receptor (AR)dependent and AR-independent mechanisms to resist AR-targeted therapies in castrationresistant prostate cancer (CRPC). While the AR signaling axis remains the cornerstone for therapeutic development in CRPC, a clearer understanding of the heterogeneous biology of CRPC tumors is needed for innovative treatment strategies. In this review, we discuss the characteristics of CRPC tumors that lack AR activity and the temporal and spatial considerations for the conversion of an AR-dependent to an AR-independent tumor type. We describe the more prevalent treatment-emergent phenotypes arising in the CRPC disease continuum, including amphicrine, AR-low, double-negative, neuroendocrine and small cell phenotypes. We discuss the association between the loss of AR activity and tumor plasticity with a focus on the roles of transcription factors like SOX2, DNA methylation, alternative splicing, and the activity of epigenetic modifiers like EZH2, BRD4, LSD1, and the nBAF complex in conversion to a neuroendocrine or small cell phenotype in CRPC. We hypothesize that only a subset of CRPC tumors have the propensity for tumor plasticity and conversion to the neuroendocrine phenotype and outline how we might target these plastic and emergent phenotypes in CRPC. In conclusion, we assess the current and future avenues for treatment and determine that the heterogeneity of CRPCs lacking AR activity will require diverse treatment approaches.
\end{abstract}
Key Words
- castration-resistant prostate cancer
- androgen receptor
- adenocarcinoma
- amphicrine
- double-negative prostate cancer
- AR-low
- neuroendocrine

\section{Castration-resistant prostate cancer}

Prostate cancer (PC) is notable for the dependence of tumor cells on the androgen receptor (AR) for activation of a luminal differentiation program, proliferation and survival. Because of this, androgen deprivation therapy
(ADT), achieved through surgical or pharmacological approaches, is the principal treatment for men with metastatic PC. Tumors from the vast majority of men $(>80 \%)$ respond initially to ADT. However, ADT is not curative and 
treatment-resistance typically develops after several years. This disease state, known as castration-resistant prostate cancer (CRPC), is marked by the maintenance of AR signaling and continued PC reliance on androgens. Several genetic mechanisms that maintain $A R$ activity have been identified, including amplification of the AR gene or an upstream enhancer that increases AR expression (Quigley et al. 2018, Takeda et al. 2018). Moreover, in many cases, intra-tumoral androgen production or conversion of steroid precursors from the adrenal gland and AR splice variants also contribute to sustained AR activation, representing targets for therapeutic intervention (Montgomery et al. 2008, Hu etal. 2009, Sharp etal. 2019). Examples include the second-generation AR antagonists such as enzalutamide, darolutamide, and apalutamide (Andersen et al. 2010, Fizazi et al. 2020, Smith et al. 2021), and inhibitors of androgen biosynthesis enzymes such as abiraterone (Barrie et al. 1994). All of these drugs improve overall survival in men with CRPC, and are the current standard of care (de Bono et al. 2011, Scher et al. 2012). However, complete remissions using second-line $\mathrm{AR}$ pathway inhibitors are rare and resistance is nearly universal. This has led to the development of novel pharmacological approaches to further suppress AR activity in PC. These include the development of EPI-001 to target the N-terminal of the AR and block the transcriptional activity of full-length AR and its splice variants (Myung et al. 2013, De Mol et al. 2016). It also includes an evolving array of Proteolysis Targeting Chimeras (PROTACs) that target the AR for degradation: ARD-61, ARD-69, ARCC-4, TD-802 and MTX-23 (Salami et al. 2018, Han et al. 2019, Kregel et al. 2020, Lee et al. 2021, Takwale et al. 2020). Significantly, MTX-23 targets both the AR-variant V7 and full-length AR using proteasomemediated proteolysis (Lee et al. 2021).

\section{Emerging phenotypes in CRPC}

With the advent of more effective therapies targeting the AR pathway, we and others have observed the emergence of tumors employing multiple AR-dependent mechanisms that contribute to resistance to AR-targeted therapies. These AR-dependent resistance mechanisms maintain a luminal differentiation program with sustained AR signaling without evidence of switching to an alternate differentiation program, most notably neuroendocrine (NE) PC. We have termed these tumors AR active without $\mathrm{NE}$ differentiation (AR+/NE-). However, an expanding literature highlights the increasing incidence of additional
CRPC phenotypes that were previously rare prior to more widespread use of second-generation AR inhibitors (Bluemn et al. 2017). Indeed, our group characterized four additional CRPC subtypes based on the expression of established AR or NE genes. These subtypes are: (i) amphicrine; (ii) AR-low; (iii) double-negative; and (iv) small cell or neuroendocrine CRPC phenotypes (Labrecque et al. 2019). Amphicrine cells were first described by Walter and Ratzenhofer (Walter \& Ratzenhofer 1979) as endocrine cells with both endocrine and exocrine functions. Amphicrine CRPC retains AR activity and luminal differentiation programs but expresses some of the classical markers of NE disease (e.g. chromogranin A, synaptophysin, and/or CD56). For the purposes of this review, we describe the amphicrine phenotype as tumors composed of cells co-expressing $\mathrm{AR}$ and $\mathrm{NE}$ genes $(\mathrm{AR}+/ \mathrm{NE}+)$. The AR-low phenotype displays decreased nuclear AR and decreased $\mathrm{AR}$ regulated genes while in many cases maintaining expression of KLK3 (i.e. prostate-specific antigen; PSA), an AR-regulated gene (ARlow/NE-) (Labrecque et al. 2019). Double-negative prostate cancer (DNPC) tumors are denoted by undetectable AR protein expression and absent $\mathrm{AR}$ or NE gene expression (AR-/NE-). DNPC phenotypes include rare CRPC tumors with squamous differentiation (Parwani et al. 2004, Labrecque et al. 2019, Cackowski et al. 2020). Lastly, small cell or NE prostate cancer (SCNPC) tumors are AR-null and have either classical small cell pathology or upregulated NE gene expression profiles without AR activity (AR-/NE+) (Tsai et al. 2017, Beltran et al. 2019a, Labrecque et al. 2019) (Table 1). Importantly, further refinement of CRPC classes and discovery of novel CRPC phenotypes are likely with the widespread availability of DNA and RNA sequencing datasets and continued collection and analysis of CRPC tissues (Abida et al. 2019, Labrecque et al. 2019). Thus, the shifting landscape of CRPC phenotypes in response to therapy requires the development of effective therapeutic strategies that target the diverse array of emerging aggressive tumor phenotypes that are either AR-dependent or the emerging subtypes that no longer rely on AR activity.

\section{What is androgen receptor inactive prostate cancer?}

Classically, the AR-inactive CRPC phenotype is defined by the complete loss of AR expression in PC tumor cells (Beltran et al. 2016). However, the majority of patients who die of CRPC maintain some degree of AR expression (c) 2021 Society for Endocrinology Published by Bioscientifica Ltd. Printed in Great Britain 
Table 1 Terminology and features used to describe CRPC subtypes.

\begin{tabular}{|c|c|}
\hline Acronym & Definition \\
\hline AMPC & Amphicrine prostate cancer \\
\hline ARLPC & AR-low prostate cancer \\
\hline ARPC & AR-high prostate cancer \\
\hline CRPC & Castration-resistant prostate cancer \\
\hline DNPC & Double-negative prostate cancer \\
\hline NEPC & Neuroendocrine prostate cancer \\
\hline SCNPC & Small cell or neuroendocrine prostate cancer \\
\hline SCPC & Small cell prostate cancer \\
\hline
\end{tabular}

and activity as evidenced by rising levels of serum PSA at the time of disease progression or death. Notably, the presence of AR and PSA expression does not necessarily equate with responsiveness to ADT. For example, AR mutations (Newmark et al. 1992, Gaddipati et al. 1994), AR amplification and rearrangements (Koivisto et al. 1997, Li et al. 2020b), amplification of AR enhancer elements (Takeda et al. 2018), the expression of AR splice variants that lack the C-terminal ligand-binding domain (Zhang et al. 2011, Li et al. 2012, Sharp et al. 2019), enhancer RNAs (Hsieh et al. 2014), and altered AR co-regulators (Reebye et al. 2012) promote resistance to AR directed therapies.

We, however, contend that not all CRPC tumors expressing AR and PSA are the same. Specifically, these cells harbor all of the clinical markers to suggest an AR-dependent phenotype, but do not require AR activity for regulating tumor cell proliferation and/or survival. This is exemplified in patients treated with ADT, where a small number of AR- and PSA-positive tumors demonstrate a loss of AR signaling and are refractory to therapy (Kumar et al. 2016). Furthermore, recent work demonstrated that AR expression in tumor cells was not a reliable predictor of response to the second-generation AR inhibitor enzalutamide; importantly, that study demonstrated that tumors from non-responders had significantly lower AR transcriptional activity despite similar protein expression as responders (Alumkal et al. 2020). Figure 1A is an RNA sequencing (RNA-Seq) heatmap of 270 CRPC biopsies from the SU2C series. Biospecimens are stratified according to the $\log _{2}$ FPKM values of $A R$ and further stratified based on an AR-regulated gene set GSVA enrichment score; ARG10 (Bluemn et al. 2017). Of note, a subset of adenocarcinoma with upregulated $A R$ transcript expression display AR activity scores as low as AR-null tumors (Fig. 1A).
The $A R$ transcript is present at high levels, but AR activity is decreased relative to other AR-expressing adenocarcinoma. When 20 AR-expressing adenocarcinoma specimens with the highest and lowest ARG10 scores were compared to each other in a gene set enrichment analysis (GSEA), the hallmark pathways androgen-response, protein-secretion and oxidative-phosphorylation were the highest pathways present in the ARG10-high group (Fig. 1B). Conversely, epithelial-mesenchymal-transition was the highest pathway in the ARG10-low group (Fig. 1B). Importantly, many of these same gene sets were activated in AR-positive, but not in AR activity-low metastatic CRPC tumors that were most resistant to enzalutamide in our recent work (Alumkal et al. 2020). We propose that the ARG10-low group - even though they display high expression of $A R, K L K 3$, and NKX3-1 transcripts - may no longer be dependent on the AR for survival and proliferation.

In parallel, molecular profiles of CRPC biospecimens from the rapid autopsy program at the University of Washington recapitulate the SU2C observations, with a subset of AR-expressing adenocarcinomas displaying reduced AR activity scores by RNA-Seq, interestingly showing a reduction in nuclear AR, but maintaining PSA protein expression by IHC (Fig. 1C). Our group and others have also observed an AR-low phenotype where there is heterogeneous or decreased AR expression (Aggarwal et al. 2019, Labrecque et al. 2019, Alumkal et al. 2020). These tumors are losing AR expression and AR activity and appear to be transitioning to an AR-null phenotype (Fig. 1C). Importantly, PSA expression (the marker most heavily relied on to assess AR activity in CRPC patients) only displays a gradual decline with the loss of AR activity in these tumors. Furthermore, NKX3-1 expression - that is considered a surrogate for AR activation in PC - displays https://erc.bioscientifica.com

https://doi.org/10.1530/ERC-21-0002 (c) 2021 Society for Endocrinology Published by Bioscientifica Ltd. Printed in Great Britain 

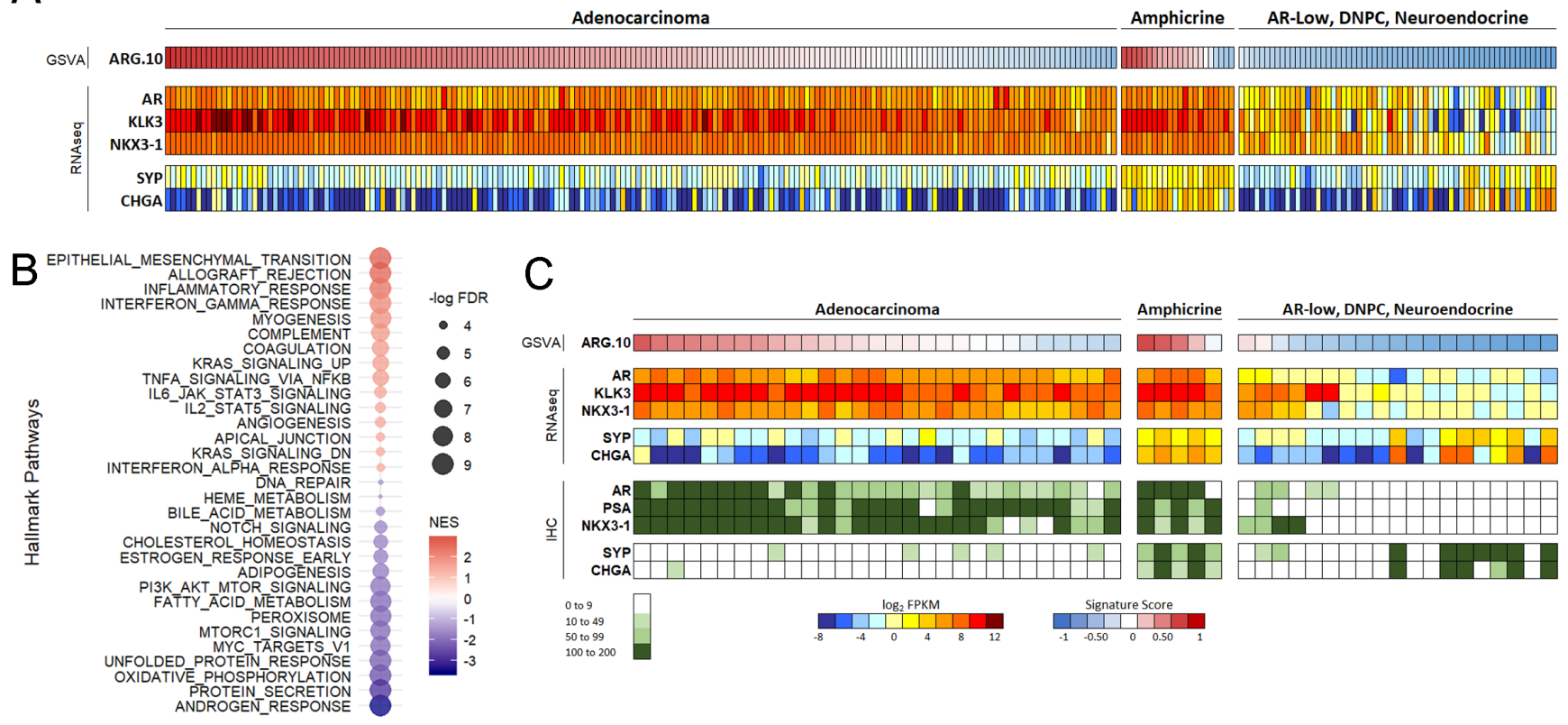

C
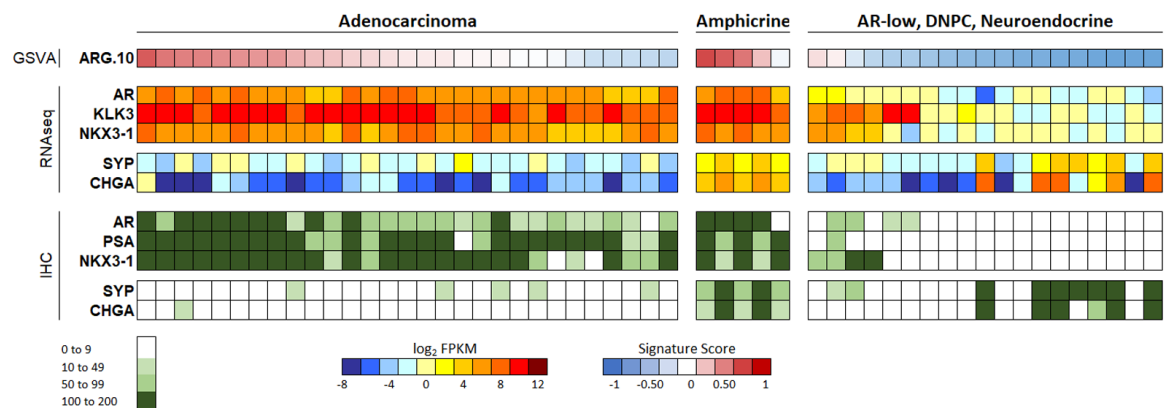

Figure 1

Molecular profiling of metastatic CRPC reveals a heterogeneous disease. (A) RNA-Seq of metastatic CRPC (MCRPC) specimens from the SU2C dataset $(n=270)$. The GSVA ARG.10 score represents androgen activity. AR - androgen receptor, KLK3 - prostate-specific antigen/PSA, and NKX3-1 are shown as examples of prostate adenocarcinoma-associated genes, and CHGA - chromogranin A, and SYP - synaptophysin as neuroendocrine-associated genes. Results are expressed as $\log _{2}$ fragments per kilobase of transcript per million mapped reads (FPKM) and colored according to scale. (B) Gene Set Enrichment Analysis (GSEA) of hallmark pathways to determine pathway enrichment in twenty specimens with the lowest GSVA ARG.10 score compared to twenty specimens with the highest GSVA ARG.10 score from the adenocarcinoma group in the SU2C dataset. Pathways positively enriched in the ARG.10-low group are shown at the top of the plot while pathways negatively enriched in the ARG.10-low group are shown at the bottom of the plot, colored by the normalized enrichment score (NES) scale shown, with the size of dots proportional to the FDR significance level. (C) RNA-Seq of mCRPC specimens acquired through rapid autopsy from 2010 to $2017(n=53)$. Similar to (A) above, GSVA ARG.10 score, adenocarcinoma and neuroendocrineassociated genes are shown along with immunohistochemistry (scores from 0 (no staining), to 200 (intense staining)) of the same mCRPC sites using antibodies to AR, PSA, NKX3-1, SYP and CHGA.

an even more gradual decline in AR-low tumors (Fig. 1C) (Abate-Shen et al. 2008, Gan et al. 2019). How AR expression is suppressed and whether AR-low tumors represent an intermediate state between AR-high and AR-null CRPC or represent a stable CRPC phenotype, themselves, remain unanswered at this time.

We propose that AR inactivity is a continuum ranging from tumors that completely lack AR expression and AR activity, 'AR-null' on one extreme, to tumors that still express the AR and some markers of AR function, like PSA and NKX3-1, but have lost dependence on the AR for tumor cell survival and/or proliferation. An important question is whether tumors that express the AR, but lack evidence of AR target gene activity, are truly AR-inactive? Would methods that ablate AR expression in these tumors have any effect on growth or survival? Would exposing these tumors to AR ligands that activate AR signaling lead to proliferation or terminal differentiation? Ongoing work in the field seeks to better define AR indifference in appropriate clinical contexts.

\section{Characteristics of CRPCs lacking AR activity}

The complexity surrounding the transition from an AR-dependent to an AR-inactive phenotype has made it difficult to define histological or molecular features that consistently associate with the emerging CRPC phenotypes. Currently, no morphological characteristics have been described in clinical specimens to delineate an AR-active from an AR-inactive phenotype in AR-expressing CRPC. Furthermore, it is not yet clear that morphological features associate with the full spectrum of molecular phenotypes of NE CRPC (Epstein et al. 2014, Aggarwal et al. 2019, Labrecque et al. 2019). Additionally, genomic analyses of patient metastases have not clarified genomic features that reliably distinguish these phenotypes or that can be used to predict the risk of conversion to AR-null or NE-positive states. For example, bi-allelic loss of the tumor suppressor genes $R B 1$ and TP53 are enriched in the NE phenotype. However, not all CRPC tumors that exhibit bi-allelic loss of RB1 in conjunction with TP53 
alterations are NE tumors (Ku et al. 2017, Aggarwal et al. 2019, Nyquist et al. 2020). In addition, loss of the tumor suppressor PTEN alone or in concert with TP53 alterations in CRPC mouse models have demonstrated concomitant decreases in AR expression (Zou et al. 2017, Liu et al. 2019b). Moreover, combinatorial PTEN/TP53 alterations accentuate NE lineage switching from luminal CRPC cells in response to AR pathway inhibition (Zou et al. 2017). On the other hand, and similar to the RB1/TP53 relationship, PTEN/TP53 alterations are not universal features of tumors with AR-loss or NE conversion in patient biospecimens (Conteduca et al. 2019). This suggests that these genomic alterations may be neither necessary nor sufficient for NE differentiation, despite their role in promoting AR-loss. Recent literature strongly suggests that epigenetic events are also important contributing factors for the development of phenotypes that are functionally independent of AR signaling (Clermont et al. 2015, Kleb et al. 2016, Lee et al. 2018a).

\section{The temporal and spatial considerations for the clinician during the conversion of an AR-dependent to an AR-independent neuroendocrine tumor type}

Currently, there are significant challenges in determining whether a specific patient's tumor is converting to an AR-inactive state. The issue primarily rests on the interpretation of limited clinical markers that can denote an AR-inactive state. In extreme cases, such as SCNPC conversion, serum PSA levels decline with a concomitant increase in tumor volume or clinical deterioration. This may be accompanied by an increase in serum chromogranin A or other NE markers. However, to complicate matters, amphicrine tumor cells co-express AR, AR target genes and classic NE biomarkers (i.e. chromogranin A or synaptophysin). The NE aspect of the amphicrine phenotype may cause the physician to interpret an increase in serum chromogranin $\mathrm{A}$ as the beginning of a transition to an AR-null SCNPC phenotype. However, there is nothing to suggest that amphicrine tumors are less responsive to AR-directed therapy than AR-high adenocarcinomas (i.e. AR+/NE-). For example, the VCaP CRPC cell line displays an amphicrine molecular profile, but is responsive to enzalutamide treatment (Tran et al. 2009, Labrecque et al. 2019).

Sampling CRPC tumors and obtaining a molecular profile is currently the most effective means of determining the intermediate transitory state from an AR-high adenocarcinoma to a poorly differentiated NE phenotype. However, metastatic biopsies has not been considered standard of care, and it is even rarer to perform sequential tumor biopsies, thus limiting our understanding of the patient's tumor phenotype. In addition, a biopsy only samples one lesion, even though a patient may have some metastases that are AR-high and responsive to ADT, while other metastases have converted to an AR-low, DNPC or SCNPC phenotype (Labrecque et al. 2019). Inter- and intratumoral heterogeneity within a patient is not uncommon in heavily treated patients with some tumors displaying conversion to SCNPC and other tumors containing a mix of AR+ and AR-null tumor cells within the same site. This work is highlighted in biopsies from patients with CRPC that demonstrate spatial and temporal intra-patient heterogeneity (Aggarwal et al. 2019), and in rapid autopsy specimens from patients with CRPC, where multiple sites are available for analysis from the same patient providing information that cannot be ascertained from a single biopsy (Zhang et al. 2015, Labrecque et al. 2019). The molecular characterization of circulating tumor cells (CTC) could be used in some cases to overcome sampling bias and tumor heterogeneity (Scher et al. 2017). However, challenges remain, with limited CTC available for analysis in patients with low tumor burden. In contrast to phenotypic changes, evaluating a single metastasis for genomic alterations provides a reasonable assessment of the major oncogenic driver events that are present in disseminated tumors within an individual, though DNAsequencing-only based approaches clearly do not provide a complete assessment of a tumor's transcriptional program (Kumar et al. 2016).

\section{What exactly is the definition of the neuroendocrine phenotype in CRPC?}

SCNPC is the most extreme AR-inactive subset vs AR-high adenocarcinoma. NE cells in the prostate are defined in current practice by immunohistochemical positivity for either synaptophysin, chromogranin A, or CD56 (Epstein et al. 2014). For some time neuroendocrine PC (NEPC) was considered a rare variant in localized hormone naïve PC. In fact, the field was somewhat dismissive of NE tumors in PC as rare and therefore not a significant focus for funding. NE tumors had been described in and appeared to be more prevalent in CRPC following ADT (Hirano et al. 2004, Beltran et al. 2011, Zhang et al. 2015). However, the implementation of second-generation AR signaling inhibitors that mediate total androgen blockade have 
resulted in increased incidences of treatment-emergent NE tumors (Bluemn et al. 2017, Aggarwal et al. 2019, Beltran et al. 2019a, Labrecque et al. 2019). On this point, we need to take a step back. An NE tumor is defined in current practice by morphological characteristics and supported by immunohistochemical positivity for either synaptophysin, chromogranin A, or CD56 (Epstein et al. 2014). However, there have been a plethora of articles describing NE CRPC that do not use these specific criteria and that rely on morphologic features alone. While morphology may be an acceptable surrogate for small cell in de novo tumors that have not undergone ADT, it is possible that ADT or secondgeneration $\mathrm{AR}$ inhibitors induce morphologic changes that mirror NEPC, but without NE gene expression. Additionally, since the conversion of adenocarcinoma to an AR-null NE phenotype is most likely a continuum of disease, many models and tumor specimens have some $\mathrm{NE}$ molecular characteristics, but have not completely transitioned to a SCNPC phenotype (e.g. amphicrine tumors). Due to the presence of diverse transitory and differentiated NE phenotypes, we would suggest from a molecular standpoint that the SCNPC phenotypes as a group could be identified by either synaptophysin, chromogranin A, or CD56 positivity and the lack of AR expression.

\section{AR indifference is associated with the loss of $A R$ and gain of tumor plasticity}

Characterization of the $A R$ gene and promoter region, and of factors inducing AR expression have been explored over the last few decades. The $A R$ promoter region lacks a typical TATA box and AR expression across human tissues has been reported to be mediated, in part, by SP1 activity (Tilley et al. 1990, Faber et al. 1993). Additionally, cyclicAMP induces AR expression and cyclic-AMP response elements (CRE) alongside CREB transcription factor binding in the AR promoter have been verified (Lindzey et al. 1993, Mizokami et al. 1994). In the context of CRPC, AR transcript and protein expression are directly induced through E2F1 activity in CRPC cells lacking RB expression (Sharma et al. 2010). Additionally, EZH2 and EED activity induce AR expression, directly associate with AR protein and are coactivators of AR transcription factor functions independent of canonical polycomb repressive complex 2 (PRC2) functions in PC (Xu et al. 2012, Kim et al. 2018, Liu et al. 2019a). However, the relationship between AR and polycomb group proteins is a complicated one as there is evidence to suggest that epigenetic regulation through

(c) 2021 Society for Endocrinology Published by Bioscientifica Ltd. Printed in Great Britain
EZH2 contributes to AR-loss (Kleb et al. 2016). This is supported by work showing that $\mathrm{EZH} 2$ inhibitors reactivate AR expression in AR-null NE models (Beltran et al. 2016, Kleb et al. 2016). Another mechanism that may suppress AR expression is DNA methylation. Kinoshita et al. identified consensus sites of DNA methylation in the $A R$ promoter that are markers for gene silencing and surmized that $A R$ DNA methylation may represent a phenotype important in the development of hormone independence in a subset of advanced PC that has lost AR expression (Kinoshita et al. 2000). Together, these data suggest that tumor cells that lose AR expression through epigenetic alterations are inherently more plastic than tumor cells that continue to express AR and have AR activity throughout ADT. This notion has led to the proposed use of epigenetic modifier inhibitors to reverse AR-loss and re-sensitize AR-inactive tumors to AR pathway inhibitors.

\section{Loss of AR, the expression of SOX2 and the activation of LSD1 promotes NE differentiation in CRPC}

If the conversion of an AR-active adenocarcinoma to an AR-null NE phenotype is an epigenetic phenomenon, then key players in the physiologic transition to a neuronal phenotype could drive the transdifferentiation process in CRPC. Alongside the silencing of AR expression in CRPC, SOX2 is expressed in many AR-null NE CRPC tumors and model systems (Yu et al. 2014, Kanan et al. 2019). SOX2 is an AR-repressed transcription factor that promotes lineage plasticity through epigenetic reprogramming (Kregel et al. 2013, Mu et al. 2017). In addition, SOX2 is considered a neural stem cell marker (Ellis et al. 2004) and has roles in neuronal development through maintaining neural progenitor identity and inhibiting neuronal differentiation (Uwanogho et al. 1995, Graham et al. 2003). Recent studies overexpressing SOX2 in LNCaP cells revealed an increase in NE gene expression, however, a complete transition to an AR-null or NE phenotype was not observed (Li et al. 2020a, Metz et al. 2020). It has been posited that SOX2 expression is permissive, but not sufficient for NE conversion in CRPC (Kwon et al. 2020a,b). Of note, SOX2 is active in neural progenitor cells, but not in differentiated postmitotic neurons (Miyagi et al. 2004). Thus, the continued expression of SOX2 in NE tumors potentially contributes to a tumor phenotype that is more plastic in nature than AR expressing tumors (Mu et al. 2017, McAuley et al. 2019). With the loss of AR expression, SOX2 activity promotes further epigenetic alterations, including upregulation 
of the histone demethylase LSD1, suppression of adenocarcinoma-associated genes, and upregulation of $\mathrm{NE}$ programs, all of which may contribute to NE conversion ( $\mathrm{Li}$ et al. 2020a). An alternatively spliced form of LSD1, known as LSD1+8a that is normally only expressed in neuronal tissues, was recently found to be expressed in NEPC tumor cells, and LSD1 splicing was mediated by SRRM4 (Coleman et al. 2020). In neuronal cells, LSD1+8a appears to have substrate-specificity for the repressive mark H3K9, as opposed to LSD1's canonical histone demethylation substrate H3K4, and demethylation of H3K9 by LSD1+8a enhances neuronal gene expression in neuronal cells (Laurent et al. 2015, Jotatsu et al. 2017, Coleman et al. 2020). More work is needed to determine if this LSD1+8a function is conserved in NE CRPC tumors.

\section{SOX2 and the nBAF complex promote a proliferative NE phenotype}

Another epigenetic modifying complex critical for neuronal differentiation is the neuronal BAF (nBAF) complex. The BAF (mammalian SWI/SNF) complex, is a chromatin remodeling complex that regulates gene expression and cell differentiation states (Alfert et al. 2019). Brg1 is a subunit of the SWI/SNF complex involved in neurogenesis, neural crest induction, and differentiation (Eroglu et al. 2006). Seo et al. demonstrated in Xenopus that the loss of Brg1 function did not affect neural induction or neural cell fate determination. However, Brg1-loss induced the expansion of a proliferative Sox2positive neural progenitor cell population and diminished the expression of a terminally differentiated neuronal marker, suggesting that Brg1 is required for neuronal differentiation (Seo et al. 2005). Recent work by Cyrta et al. in prostate tumor cells recapitulate these findings; they found that BRG1 expression in CRPC was positively correlated with the expression of synaptophysin, but also showed a tendency toward positive correlation with SOX2 (Cyrta et al. 2020). Likewise, Lessard et al. determined that BAF45A and BAF53A subunits are necessary and sufficient for neural progenitor proliferation and are replaced by BAF45B, BAF53B, and BAF45C to form the nBAF complex as neural progenitors exit the cell cycle (Lessard et al. 2007). These data demonstrate that SOX2 is associated with an expanding neural progenitor phenotype and that a switch from BAF to nBAF complexes through the insertion of BAF45B, BAF53B, and BAF45C is associated with the transition of a neural progenitor cell to a terminally differentiated neural phenotype. It is important to note that NE CRPC cells are not terminally differentiated, but are in fact highly proliferative. This suggests that the expression of SOX2, and the formation and activity of the nBAF complex provides for a proliferative stem-like NE phenotype in PC (Cyrta et al. 2020). Additionally, it is important to note that this behavior occurs in the absence of the AR. As mentioned previously, it is possible to revert AR-null NE cells back to an AR-positive phenotype in some NE CRPC models (Beltran et al. 2016, Kleb et al. 2016). This implies that the continued expression of SOX2 and the nBAF complex could represent central components of the plastic and proliferative aspect of the NE phenotype in CRPC.

\section{Changes in components of the BAF complex can promote the NE phenotype in AR-null PC tumors}

Under AR pathway suppression with pharmacological agents, there is an increase in the prevalence of SCNPC and amphicrine tumors in metastatic CRPC (Labrecque et al. 2019). These two CRPC phenotypes can arise in part due to the loss of RE1-silencing transcription factor (REST) activity. REST is a master regulator of differentiation that transcriptionally represses neuronal programs in nonneuronal cells. Thus, loss of REST repressor activity in both AR-active and AR-null tumors induces NE gene expression, such as SYP, and results in the amphicrine and SCNPC phenotypes respectively (Labrecque et al. 2019). RNA splicing factors SRRM3/SRRM4 diminish REST repressor activity through a splicing-in event, producing a REST transcript that encodes a truncated REST protein variant (REST4) in prostate and other cell types (Zhang et al. 2015, Li et al. 2017, Nakano et al. 2019). Diminished canonical REST activity through REST4 alternative splicing is a hallmark of neuronal cells that allows for the expression of RESTrepressed genes, many of which are NE factors or proteins involved in the vesicular secretion of NE factors. However, the loss of REST activity also induces the expression of BAF53B in PC (Cyrta et al. 2020). As stated earlier, BAF53B is part of the nBAF complex, a neuronal chromatin remodeling complex that regulates gene expression and differentiation (Alfert et al. 2019). Post-mitotic neurons express BAF53B (Vogel-Ciernia et al. 2013) promoting a fate-determining chromatin switch to a differentiated neuronal phenotype (Olave et al. 2002, Tang et al. 2013). Yoo et al. determined that in the vertebrate nervous system, a switch in chromatin-remodeling appears to coincide with the final mitotic division of neurons. This switch involves 
the exchange of the BAF53A and BAF45A subunits within the BAF complex for the homologous BAF53B and BAF45B subunits within neuron-specific BAF (nBAF) complexes in post-mitotic neurons (Yoo et al. 2009). There is a definitive increase in BAF53B at the transcript and protein level in NE CRPC and in the majority of (but not all) amphicrine CRPC metastases (Labrecque et al. 2019). BAF45B transcript is elevated in AR-null NE CRPC, but it is not elevated in amphicrine CRPC metastases, indicating that the complex may be active specifically in AR-null NE CRPC tumors (Labrecque et al. 2019, Cyrta et al. 2020). This suggests that $B A F 45 B$ is not a REST repressed message and in the absence of BAF45B, BAF53B may not be sufficient to form the nBAF complex in AR-positive amphicrine tumors. Therefore, if the AR is present, the expression of the REST-repressed chromatin modifier BAF53B alone has no impact on gene expression and can result in the amphicrine phenotype in CRPC, where only REST-repressed transcripts and not downstream master regulators of SCNPC are expressed (Labrecque et al. 2019).

\section{How does the loss of $A R$, the expression of SOX2 and the loss of RB1 in neuroendocrine CRPC fit into this picture?}

SOX2 is an AR-repressed transcription factor (Kregel et al. 2013). PC stem cell-like intermediates have reduced RB1 and TP53 protein expression and overexpress SOX2 (Nouri et al. 2020). In PC, it has been argued that lineage plasticity is enabled by the loss of TP53 and RB1 function, which is mediated by increased expression of the reprogramming transcription factor SOX2, and can be reversed by restoring TP53 and RB1 function or by inhibiting SOX2 expression ( $\mathrm{Mu}$ et al. 2017). Sutter et al. have shown that inactivation of the tumor suppressor genes RB1 and TP53 in neural stem cells induced deregulated proliferation and resistance to apoptosis in vitro. Moreover, injection of these cells into mice formed medulloblastomas and that medulloblastomas originating from the neural stem cells preferentially expressed stem cell markers including SOX2 (Sutter et al. 2010). The expression of SOX2 is also high in the pediatric tumor retinoblastoma in which $R B 1$-loss is ubiquitous, highlighting the discordance between the physiological process where neural precursors convert to terminally differentiated neurons and the maintenance of SOX2 expression in conjunction with RB1-loss in NE disease (Tong et al. 2015, Orellana et al. 2016). This suggests that there is a link between the loss of AR, the upregulation of SOX2, the loss of RB1 and the emergence of the NE CRPC phenotype. However, it must be noted that RB1-loss is not only associated with NE CRPC, it also occurs in AR-positive CRPC (Nyquist et al. 2020). Nyquist et al. determined that CRISPR-Cas9-mediated double knockout of RB1 and TP53 alone does not induce SOX2 expression or promote a plastic or NE phenotype in AR-positive LNCaP cells. Furthermore, the AR-null LNCaP derivative APIPC does not convert to the NE phenotype (Bluemn et al. 2017). These data suggest that there are various pathways to the NE phenotype involving SOX2 and RB1-loss. Identifying these pathways will be critical to predict the patients who are at a greatest risk of NE conversion and to develop therapies that block this process.

\section{Only a subset of CRPC tumors may have the propensity for tumor plasticity and conversion to the NE phenotype}

Although the incidences of AR-low, DNPC and NE tumors are rising in end-stage CRPC, the majority of CRPC metastases retain robust AR expression (Bluemn et al. 2017, Aggarwaletal.2018). This suggests that only a subset of CRPC metastases have the propensity to lose AR expression after ADT and newer AR pathway inhibitors. The proportion of patients that fall into AR-inactive categories may represent a larger cohort over time with the introduction of more effective AR blockade, but recent work suggests that some AR-expressing tumors - particularly those that respond poorly to enzalutamide - have lower canonical AR activity (Alumkal et al. 2020).

There are several possible explanations for how the loss of AR expression and NE transdifferentiation may occur in a PC tumor cell. One possible explanation is that activation of the PRC2 complex leads to loss of AR expression and induction of AR-repressed SOX2. Similar to neural precursor cells, SOX2 could then poise the epigenetic landscape for activation of NE differentiation programs by neuronal transcription factors (AmadorArjona et al. 2015). At the same time, sustained AR blockade can upregulate SRRM4, a splicing factor that promotes neural differentiation through REST alternative splicing and inactivation in PC (Raj et al. 2011, Zhang et al. 2015, Li et al. 2017, 2019). REST inactivation induces the expression of BAF53B in PC (Cyrta et al. 2020). BAF53B and BAF45B are present in NE CRPC cells and are principal components of the nBAF complex that promotes neuronal gene expression in CRPC (Cyrta et al. 2020) (Fig. 2). If these changes do not occur, a DNPC phenotype without NE differentiation may predominate. The propensity to escape AR blockade 


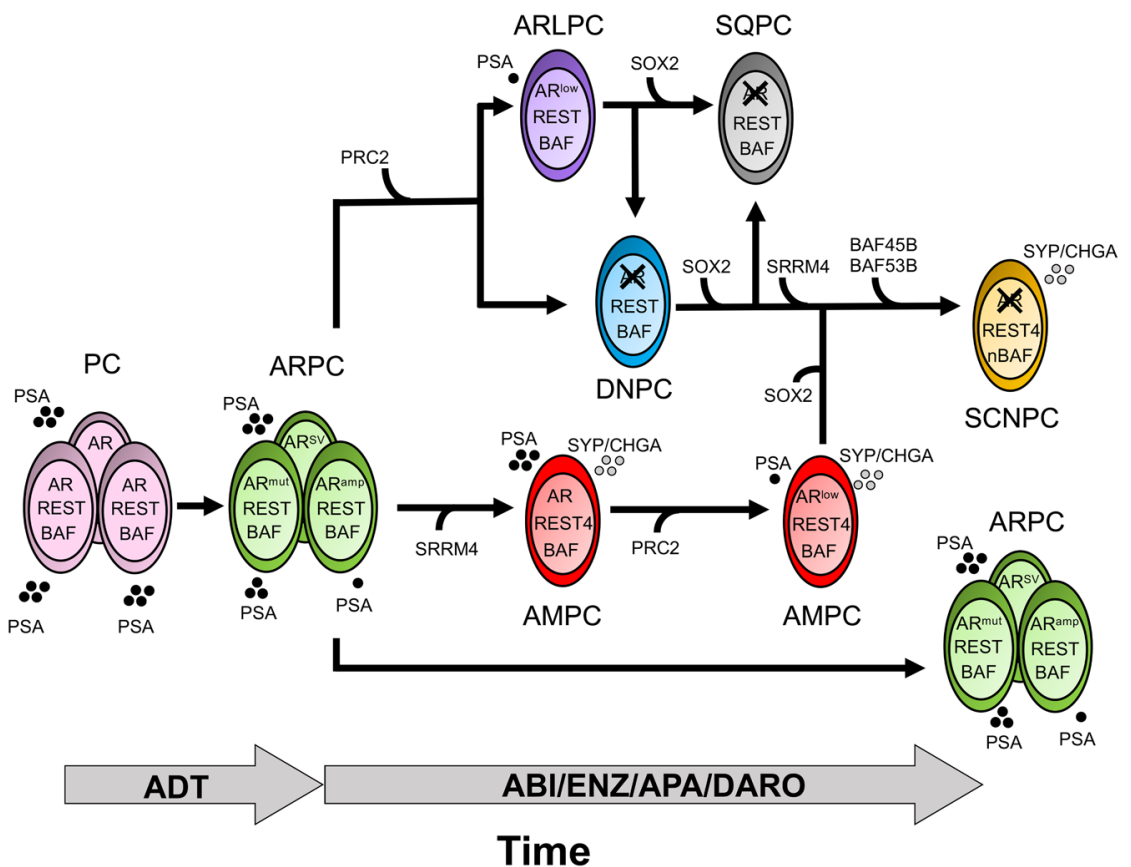

Figure 2

Schematic of the metastatic CRPC disease continuum with regulators and biomarkers of cellular differentiation states. Prostate cancer $(P C)$, AR-high PC (ARPC), AR-low PC (ARLPC), amphicrine $P C$ (AMPC), double-negative PC (DNPC), small cell or neuroendocrine prostate cancer (SCNPC), squamous prostate cancer (SQPC), AR mutations (ARmut), AR amplification (ARamp), AR splice variants (AR ${ }^{S V}$ ), prostate-specific antigen (PSA), chromogranin A (CHGA) synaptophysin (SYP), androgen deprivation therapy (ADT), abiraterone (ABI), enzalutamide (ENZ), apalutamide (APA), darolutamide (DARO). through the loss of AR expression, SOX2 expression and the NE phenotype could also depend on the tumor cell of origin. This population of tumors could arise from tumor progenitors originating in the prostate where SOX2 expression has been shown to be enriched in the epithelial cells of the proximal prostate adjacent to the urethra and is present in castration-resistant progenitor cells in the adult murine prostate (McAuley et al. 2019, Kwon et al. 2020a,b).

As described, the linear transition from an AR-expressing tumor cell to a plastic NE phenotype is only a hypothesis. There is currently no understanding if the amphicrine phenotype is an intermediary state and could eventually lose AR expression and convert to a classic NE phenotype. Similarly, in some cases, AR-low and AR-null DNPC may never convert to the classic NE phenotype. For example, we have observed a subset of DNPC tumors with squamous differentiation (Kibbee-Cram 1988, Parwani etal. 2004, Labrecque et al. 2019). While rare, this phenotype may represent an alternative differentiation pathway for plastic AR-low or AR-null DNPC tumors. This suggests that the DNPC phenotype could represent a transitory point where a prostate epithelial cell in a stem-like state could remain as a DNPC tumor, or convert to a squamous, NE, or other differentiated phenotype. The complexity of tumor cell evolution is evidenced by the key roles the cell of origin, the accumulated genomic hits, and microenvironment may all play in transition to different phenotypes. This is important to consider when interpreting the experimental manipulation of adenocarcinoma cell lines and organoids in vitro to produce a 'transdifferentiated' NE tumor cell. If the AR-inactive, AR-low and AR-null phenotypes arise based on a specific cell of origin with specific genomic alterations, and specific epigenetic alterations, then the manipulation of cell lines from an adenocarcinoma phenotype to the NE phenotype, while forced, may not be biologically relevant. There could be many pathways to the NE phenotype, but not all necessarily arise in patient tumors in response to AR blockade.

\section{Defining 'phenotype' in CRPC and the impact on clinical care in the future}

We currently rely on classic biomarkers and tissue morphology to define CRPC tumor phenotypes in the clinical setting. However, this approach will change with the expansion of 'omic' technologies and other approaches to phenotype tumors. In this commentary, we only briefly discussed the influence of genomic alterations on AR-inactive phenotypes. Rather, we have highlighted the phenotypes that lose AR activity and acquire a plastic state or differentiate to another classic tumor phenotype via epigenetic means. This does not negate the role of genomic alterations promoting lineage plasticity or differential response to therapy of a subset of tumors in a defined phenotype due to the inherited genomic alterations acquired before a change in the tumor phenotype occurs. This demands, as we have known for some time, that a 
multi-layered approach involving genomics, transcriptomics, epigenetics, and proteomics are required to define each of the treatment-emergent CRPC tumor phenotypes. More stringent definitions of these phenotypes are critically needed so that patients whose tumors exhibit a similar phenotype may be stratified to clinical trials testing agents that are predicted to work well in specific subtypes.

\section{Targeting plasticity and emergent phenotypes in castration-resistant prostate cancer}

In 1994, Bang et al. provided direct evidence of plasticity in the lineage commitment of adenocarcinoma of the prostate. They demonstrated that cAMP can drive the plasticity of prostate carcinoma cells sufficient to trigger a series of events associated with the emergence of the NE phenotype (Bang et al. 1994). A recent NCI Workshop focused on lineage plasticity and AR-independent PC described lineage plasticity as 'a biologic process that occurs during normal development and later as a mechanism that promotes cell survival when adapting to their environment, evading stress, or repairing tissues' (Beltran et al. 2019a). An example of this is the transdifferentiation of ADT-treated CRPC cells to an alternative NE cell lineage. In this case, the acquisition of an alternative cell lineage is an effective drug resistance mechanism. Understanding the disease continuum from adenocarcinoma to a classic small cell NE phenotype in CRPC could provide potential targets for treatment that were not present previously. Currently, treatment for confirmed or suspected SCNPC is a platinum-based regimen (Amato et al. 1992, Suzuki et al. 2020). However, the duration of response is short (Aparicio et al. 2013).

Cell surface markers present an opportunity for targeted drug delivery to SCNPC tumors. Carcinoembryonic antigen (CEA or CEACAM5) is enriched in SCNPC and has been suggested as a useful marker for selecting therapy (Lee et al. 2018b). Abnormal CEA levels predict poor overall survival suggesting a benefit from chemotherapy in patients with CRPC with an anaplastic feature (Aparicio et al. 2013). Further, it has been proposed as the target for an antibody-drug conjugate with efficacy in CEACAM5 expressing SCNPC patient-derived xenograft (PDX) models (DeLucia et al. 2021). Another cell surface marker, notch ligand delta-like protein 3 (DLL3) (Dunwoodie et al. 1997) is expressed in the majority of SCNPC tumors, and similar to CEACAM5 an antibody-drug conjugate that targets DLL3 has been used successfully in PDX models and in an early phase clinical trial (Puca et al. 2019). These two antibodydrug conjugates hold promise that cell surface markers associated with embryonic development could capture both a cell population transitioning to the NE phenotype and the NE phenotype itself.

Additional targets for treatment include the transcription factor MYCN and the mitotic serine/ threonine kinase AURKA. The overexpression and gene amplification of MYCN and AURKA in a significant number of NEPC tumors, and evidence that they cooperate to induce the NE phenotype in prostate cells marks these factors as exciting targets in NEPC (Beltran et al. 2011). MYCN has been established as a driver of NEPC. Using genetically engineered mouse models it has been shown that N-Myc overexpression leads to the development of poorly differentiated, invasive PC that is molecularly similar to human NEPC (Dardenne et al. 2016). Destabilization of MYCN through AURKA inhibition has been shown to significantly impact tumor growth in MYCN driven tumors (Lee et al. 2016). In a clinical trial of alisertib (a drug that inhibits the interaction between MYCN and AURKA) in men with metastatic PC, patients with tumors with molecular features supporting AURKA and MYCN activation achieved significant clinical benefit from single-agent alisertib (Beltran et al. 2019b). Another AR repressed master regulator, BRN2/POU3F2 has been shown to regulate SOX2 expression in PC, and promote NE differentiation (Bishop et al. 2017). These findings nominate BRN2 as another potential target in BRN2-expressing NEPC. Fibroblast growth factors (FGFs) and their receptors have a significant role in prostate development and PC (Kwabi-Addo et al. 2004). Our group demonstrated that a subset of AR-null PC tumors may respond to FGFR inhibition (Bluemn et al. 2017). Whether the responsiveness to FGFR inhibition relates to tumors transiting from an AR expressing to an AR-null phenotype, the DNPC phenotype or the rare squamous phenotype remains to be seen. Since the AR-inactive phenotype most likely derives from treatment-induced epigenetic events (Clermont et al. 2015, Beltran et al. 2016, Kleb et al. 2016, Lee et al. 2018a), a number of investigators are assessing epigenetic modifier inhibitors as a strategy to block or reverse the emergence of new cell lineages associated with drug treatment in CRPC.

Increased EZH2 expression has been associated with the NE phenotype in PC (Clermont et al. 2015). Furthermore, small cell lines (including NCI-H660) have silencing histone modifications (H3K27me3 and H3K9me2) in the $\mathrm{AR}$ promoter and the use of an EZH2 inhibitor resulted in AR expression and growth inhibition prompting the
(C) 2021 Society for Endocrinology Published by Bioscientifica Ltd. Printed in Great Britain 
authors to suggest that the AR-null phenotype can be reversed with epigenetic drugs (Kleb et al. 2016). Similar results have been observed in mouse models where RB1loss facilitates lineage plasticity and metastasis of prostate adenocarcinoma initiated by PTEN mutation $(\mathrm{Ku}$ et al. 2017). Additionally, MYCN also promotes an EZH2mediated transcriptional program driving NEPC, and EZH2 inhibition can reverse MYCN-induced suppression of epithelial lineage genes (Dardenne et al. 2016, Berger et al. 2019). Since silencing EZH2 is suggested to inhibit NE differentiation in PC, this makes EZH2 a prime target for therapy in NEPC.

The bromodomain and extra-terminal (BET) protein, bromodomain protein 4 (BRD4) recruits transcriptional regulatory complexes to acetylated chromatin (Dey et al. 2003) and subsequently activates RNA polymerase II-driven transcriptional elongation. As a histone acetylation reader, BRD4 is an important component of the $\mathrm{P}-\mathrm{TEFb}$ complex, where Cyclin-Dependent Kinase 9 (CDK9) heterodimerizes with a cyclin partner (cyclin $\mathrm{T}$ or $\mathrm{K}$ ) and stimulates transcriptional elongation by phosphorylating RNA polymerase II (Peterlin \& Price 2006). It is thought that BRD4 couples the P-TEFb complex to chromatin structures via binding of its bromodomains to acetylated lysines in the histone $\mathrm{H} 3$ and $\mathrm{H} 4$ tail sequences (Vollmuth et al. 2009). CDK9 phosphorylates $\mathrm{AR}$, and has been shown to mediate the reactivation of AR signaling in PC cells in vitro (Lee et al. 2001, Pawar et al. 2018).

BET inhibition has been studied in both PC preclinical models and a recent clinical trial. BET inhibition using the tool compound JQ1 disrupts AR recruitment to target gene loci (Asangani et al. 2014). ARV-771, a smallmolecule pan-BET degrader suppresses both AR signaling and AR levels (Raina et al. 2016). This suggests that BET inhibitors could enhance AR antagonism in combination with AR antagonists (Asangani et al. 2016). Other BET inhibitors include Y08060, ABBV-075, ZEN-3694, ODM207 and I-BET151 (Dawson et al. 2011, Faivre et al. 2017, Xiang et al. 2018, Aggarwal et al. 2020, Ameratunga et al. 2020). BET and CDK9 inhibitors can impact survival and proliferation programs through blocking MYC expression and activity (Faivre et al. 2017, Xiang et al. 2018, Coleman et al. 2019b). BET inhibitors suppress the growth of CRPC, including AR-null and NEPC models (Welti et al. 2018, Coleman et al. 2019a); however, the maintenance of MYC expression promotes de novo resistance to BET bromodomain inhibition in CRPC, demonstrating MYC's importance for the anti-tumor activity of BET inhibition (Coleman etal. 2019b). Significantly, due to the interactions of CDK9 and BRD4, combined CDK9+BET inhibition has been suggested as a novel therapeutic approach in cancer (Moreno et al. 2017, Pawar et al. 2018). Based on the evidence above, the activity of BET inhibitors does not appear to be limited to AR-expressing CRPC. Indeed, in neuroblastoma models, BET inhibition of MYCN impaired growth, induced apoptosis, and limited tumor growth in vivo (Puissant et al. 2013, Shahbazi et al. 2016). In clinical trials, ZEN-3694 plus enzalutamide demonstrated potential efficacy in patients with androgen-signaling inhibitorresistant CRPC. Importantly tumors with low baseline AR activity appeared to derive greater clinical benefit from treatment than those with high baseline AR activity (Aggarwal et al. 2020).

Another epigenetic modifier of interest in NEPC is LSD1 (Sehrawat et al. 2018, Etani et al. 2019). As discussed previously, Li et al. have proposed that SOX2 may promote epigenetic alterations through LSD1 and conversion to the NE phenotype (Li et al. 2020a). We also identified the splice variant LSD1+8a in NEPC, but more work is needed to determine LSD1+8a's functional rolein NEPC. Interestingly, our prior work in CRPC demonstrates that LSD1 promotes AR-independent PC cell survival and regulates gene expression independently of its demethylase function (Sehrawat et al. 2018). Thus, determining mechanisms by which LSD1 functions in NEPC will be necessary to develop the most effective class of LSD1 inhibitors.

\section{Conclusions}

The targets described above are only a few of the possible novel targets identified in the plastic AR-inactive emerging tumor phenotypes in CRPC. However, because of the complexity of these tumors, which often continue to express the AR, it will be critical to develop combinatorial therapeutic strategies targeting factors important in specific tumor subsets along with the AR. Furthermore, because of inter- and intra-patient tumor heterogeneity, it will be critical to gain a better understanding of an individual patient's phenotype. Doing so will enable a more precise selection of patients whose tumors have similar vulnerabilities for clinical trials testing agents that target these vulnerabilities.

\section{Declaration of interest}

J J A: Consulting or advisory role or speaker's fees: Merck Sharp \& Dohme, Dendreon, Astellas. Institutional research funding: Aragon https://erc.bioscientifica.com https://doi.org/10.1530/ERC-21-0002 (c) 2021 Society for Endocrinology Published by Bioscientifica Ltd. Printed in Great Britain 
Pharmaceuticals, Astellas Pharma, Zenith Epigenetics, and Gilead Sciences. P S N: Consulting or advisory role: Bristol Myers Squibb, Astellas, Janssen. The other authors have nothing to disclose.

\section{Funding}

This work was supported by a Department of Defense Idea Development Award: Partnering Principal Investigator (W81XWH-17-1-0414; W81XWH-17-1-0415), W81XWH-18-1-0347, R01CA251245, R01CA234715, U54CA224079, the Pacific Northwest Prostate Cancer SPORE/NCI (P50 CA097186); the Michigan Prostate SPORE/NCI (P50 CA186786 and P50 CA186786-07S1 through the NCI Drug Resistance and Sensitivity Network); Rogel Cancer Center Innovation Award P30 CA046592; Department of Defense (DOD) Idea Award (W81XWH-20-1-0405). M P L was supported by a Department of Defense Early Investigator Research Award (W81XWH-19-1-0729), an AACR-Bayer START Grant (18-40-44-LABR), and the Institute for Prostate Cancer Research.

\section{References}

Abate-Shen C, Shen MM \& Gelmann E 2008 Integrating differentiation and cancer: the Nkx3.1 homeobox gene in prostate organogenesis and carcinogenesis. Differentiation: Research in Biological Diversity $\mathbf{7 6}$ 717-727. (https://doi.org/10.1111/j.1432-0436.2008.00292.x)

Abida W, Cyrta J, Heller G, Prandi D, Armenia J, Coleman I, Cieslik M, Benelli M, Robinson D, Van Allen EM, et al. 2019 Genomic correlates of clinical outcome in advanced prostate cancer. PNAS $\mathbf{1 1 6}$ 11428-11436. (https://doi.org/10.1073/pnas.1902651116)

Aggarwal R, Huang J, Alumkal JJ, Zhang L, Feng FY, Thomas GV, Weinstein AS, Friedl V, Zhang C, Witte ON, et al. 2018 Clinical and genomic characterization of treatment-emergent small-cell neuroendocrine prostate cancer: a multi-institutional prospective study. Journal of Clinical Oncology 36 2492-2503. (https://doi. org/10.1200/JCO.2017.77.6880)

Aggarwal RR, Quigley DA, Huang J, Zhang L, Beer TM, Rettig MB, Reiter RE, Gleave ME, Thomas GV, Foye A, et al. 2019 Whole-genome and transcriptional analysis of treatment-emergent small-cell neuroendocrine prostate cancer demonstrates intraclass heterogeneity. Molecular Cancer Research 17 1235-1240. (https://doi.org/10.1158/15417786.MCR-18-1101)

Aggarwal RR, Schweizer MT, Nanus DM, Pantuck AJ, Heath EI, Campeau E, Attwell S, Norek K, Snyder M, Bauman L, et al. 2020 A phase Ib/IIa study of the pan-BET inhibitor ZEN-3694 in combination with enzalutamide in patients with metastatic castration-resistant prostate cancer. Clinical Cancer Research 26 5338-5347. (https://doi. org/10.1158/1078-0432.CCR-20-1707)

Alfert A, Moreno N \& Kerl K 2019 The BAF complex in development and disease. Epigenetics and Chromatin 12 19. (https://doi.org/10.1186/ s13072-019-0264-y)

Alumkal JJ, Sun D, Lu E, Beer TM, Thomas GV, Latour E, Aggarwal R, Cetnar J, Ryan CJ, Tabatabaei S, et al. 2020 Transcriptional profiling identifies an androgen receptor activity-low, stemness program associated with enzalutamide resistance. PNAS 117 12315-12323. (https://doi.org/10.1073/pnas.1922207117)

Amador-Arjona A, Cimadamore F, Huang CT, Wright R, Lewis S, Gage FH \& Terskikh AV 2015 SOX2 primes the epigenetic landscape in neural precursors enabling proper gene activation during hippocampal neurogenesis. PNAS 112 E1936-E1945. (https://doi.org/10.1073/ pnas.1421480112)

Amato RJ, Logothetis CJ, Hallinan R, Ro JY, Sella A \& Dexeus FH 1992 Chemotherapy for small cell carcinoma of prostatic origin. Journal of
Urology 147 935-937. (https://doi.org/10.1016/s0022$5347(17) 37427-\mathrm{x})$

Ameratunga M, Braña I, Bono P, Postel-Vinay S, Plummer R, Aspegren J, Korjamo T, Snapir A \& De Bono JS 2020 First-in-human phase 1 open label study of the BET inhibitor ODM-207 in patients with selected solid tumours. British Journal of Cancer 123 1730-1736. (https://doi. org/10.1038/s41416-020-01077-z)

Andersen RJ, Mawji NR, Wang J, Wang G, Haile S, Myung JK, Watt K, Tam T, Yang YC, Bañuelos CA, et al. 2010 Regression of castraterecurrent prostate cancer by a small-molecule inhibitor of the aminoterminus domain of the androgen receptor. Cancer Cell 17 535-546. (https://doi.org/10.1016/j.ccr.2010.04.027)

Aparicio AM, Harzstark AL, Corn PG, Wen S, Araujo JC, Tu SM, Pagliaro LC, Kim J, Millikan RE, Ryan C, et al. 2013 Platinum-based chemotherapy for variant castrate-resistant prostate cancer. Clinical Cancer Research 19 3621-3630. (https://doi.org/10.1158/1078-0432. CCR-12-3791)

Asangani IA, Dommeti VL, Wang X, Malik R, Cieslik M, Yang R, EscaraWilke J, Wilder-Romans K, Dhanireddy S, Engelke C, et al. 2014 Therapeutic targeting of BET bromodomain proteins in castrationresistant prostate cancer. Nature $\mathbf{5 1 0} 278-282$. (https://doi. org/10.1038/nature13229)

Asangani IA, Wilder-Romans K, Dommeti VL, Krishnamurthy PM, Apel IJ, Escara-Wilke J, Plymate SR, Navone NM, Wang S, Feng FY, et al. 2016 BET bromodomain inhibitors enhance efficacy and disrupt resistance to AR antagonists in the treatment of prostate cancer. Molecular Cancer Research 14 324-331. (https://doi.org/10.1158/1541-7786.MCR-15-0472)

Bang YJ, Pirnia F, Fang WG, Kang WK, Sartor O, Whitesell L, Ha MJ, Tsokos M, Sheahan MD, Nguyen P, et al. 1994 Terminal neuroendocrine differentiation of human prostate carcinoma cells in response to increased intracellular cyclic AMP. PNAS 91 5330-5334. (https://doi.org/10.1073/pnas.91.12.5330)

Barrie SE, Potter GA, Goddard PM, Haynes BP, Dowsett M \& Jarman M 1994 Pharmacology of novel steroidal inhibitors of cytochrome P450(17) alpha (17 alpha-hydroxylase/C17-20 lyase). Journal of Steroid Biochemistry and Molecular Biology 50 267-273. (https://doi. org/10.1016/0960-0760(94)90131-7)

Beltran H, Rickman DS, Park K, Chae SS, Sboner A, Macdonald TY, Wang Y, Sheikh KL, Terry S, Tagawa ST, et al. 2011 Molecular characterization of neuroendocrine prostate cancer and identification of new drug targets. Cancer Discovery 1 487-495. (https://doi. org/10.1158/2159-8290.CD-11-0130)

Beltran H, Prandi D, Mosquera JM, Benelli M, Puca L, Cyrta J, Marotz C, Giannopoulou E, Chakravarthi BV, Varambally S, et al. 2016 Divergent clonal evolution of castration-resistant neuroendocrine prostate cancer. Nature Medicine 22 298-305. (https://doi.org/10.1038/ nm.4045)

Beltran H, Hruszkewycz A, Scher HI, Hildesheim J, Isaacs J, Yu EY, Kelly K, Lin D, Dicker A, Arnold J, et al. 2019a The role of lineage plasticity in prostate cancer therapy resistance. Clinical Cancer Research $\mathbf{2 5}$ 6916-6924. (https://doi.org/10.1158/1078-0432.CCR-19-1423)

Beltran H, Oromendia C, Danila DC, Montgomery B, Hoimes C, Szmulewitz RZ, Vaishampayan U, Armstrong AJ, Stein M, Pinski J, et al. $2019 b$ A Phase II trial of the Aurora kinase A inhibitor alisertib for patients with castration-resistant and neuroendocrine prostate cancer: efficacy and biomarkers. Clinical Cancer Research 25 43-51. (https:// doi.org/10.1158/1078-0432.CCR-18-1912)

Berger A, Brady NJ, Bareja R, Robinson B, Conteduca V, Augello MA, Puca L, Ahmed A, Dardenne E, Lu X, et al. 2019 N-Myc-mediated epigenetic reprogramming drives lineage plasticity in advanced prostate cancer. Journal of Clinical Investigation 129 3924-3940. (https://doi.org/10.1172/JCI127961)

Bishop JL, Thaper D, Vahid S, Davies A, Ketola K, Kuruma H, Jama R, Nip KM, Angeles A, Johnson F, et al. 2017 The master neural transcription factor BRN2 is an androgen receptor-suppressed driver of https://erc.bioscientifica.com https://doi.org/10.1530/ERC-21-0002 (c) 2021 Society for Endocrinology Published by Bioscientifica Ltd. Printed in Great Britain 
neuroendocrine differentiation in prostate cancer. Cancer Discovery 7 54-71. (https://doi.org/10.1158/2159-8290.CD-15-1263)

Bluemn EG, Coleman IM, Lucas JM, Coleman RT, Hernandez-Lopez S, Tharakan R, Bianchi-Frias D, Dumpit RF, Kaipainen A, Corella AN, et al. 2017 Androgen receptor pathway-independent prostate cancer is sustained through FGF signaling. Cancer Cell 32474. e6-489.e6. (https://doi.org/10.1016/j.ccell.2017.09.003)

Cackowski FC, Kumar-Sinha C, Mehra R, Wu YM, Robinson DR, Alumkal JJ \& Chinnaiyan AM 2020 Double-negative prostate cancer masquerading as a squamous cancer of unknown primary: a clinicopathologic and genomic sequencing-based case study. JCO Precision Oncology 4 PO.20.00309. (https://doi.org/10.1200/ PO.20.00309)

Clermont PL, Lin D, Crea F, Wu R, Xue H, Wang Y, Thu KL, Lam WL, Collins CC, Wang Y, et al. 2015 Polycomb-mediated silencing in neuroendocrine prostate cancer. Clinical Epigenetics 7 40. (https://doi. org/10.1186/s13148-015-0074-4)

Coleman DJ, Gao L, King CJ, Schwartzman J, Urrutia J, Sehrawat A, Tayou J, Balter A, Burchard J, Chiotti KE, et al. 2019a BET bromodomain inhibition blocks the function of a critical AR-independent master regulator network in lethal prostate cancer. Oncogene 38 5658-5669. (https://doi.org/10.1038/s41388-019-0815-5)

Coleman DJ, Gao L, Schwartzman J, Korkola JE, Sampson D, Derrick DS, Urrutia J, Balter A, Burchard J, King CJ, et al. 2019b Maintenance of MYC expression promotes de novo resistance to BET bromodomain inhibition in castration-resistant prostate cancer. Scientific Reports 9 3823. (https://doi.org/10.1038/s41598-019-40518-5)

Coleman DJ, Sampson DA, Sehrawat A, Kumaraswamy A, Sun D, Wang Y, Schwartzman J, Urrutia J, Lee AR, Coleman IM, et al. 2020 Alternative splicing of LSD1+8a in neuroendocrine prostate cancer is mediated by SRRM4. Neoplasia 22 253-262. (https://doi.org/10.1016/j. neo.2020.04.002)

Conteduca V, Oromendia C, Eng KW, Bareja R, Sigouros M, Molina A, Faltas BM, Sboner A, Mosquera JM, Elemento O, et al. 2019 Clinical features of neuroendocrine prostate cancer. European Journal of Cancer 121 7-18. (https://doi.org/10.1016/j.ejca.2019.08.011)

Cyrta J, Augspach A, De Filippo MR, Prandi D, Thienger P, Benelli M, Cooley V, Bareja R, Wilkes D, Chae SS, et al. 2020 Role of specialized composition of SWI/SNF complexes in prostate cancer lineage plasticity. Nature Communications 11 5549. (https://doi.org/10.1038/ s41467-020-19328-1)

Dardenne E, Beltran H, Benelli M, Gayvert K, Berger A, Puca L, Cyrta J, Sboner A, Noorzad Z, Macdonald T, et al. 2016 N-Myc induces an EZH2-mediated transcriptional program driving neuroendocrine prostate cancer. Cancer Cell 30 563-577. (https://doi.org/10.1016/j. ccell.2016.09.005)

Dawson MA, Prinjha RK, Dittmann A, Giotopoulos G, Bantscheff M, Chan WI, Robson SC, Chung CW, Hopf C, Savitski MM, et al. 2011 Inhibition of BET recruitment to chromatin as an effective treatment for MLL-fusion leukaemia. Nature 478 529-533. (https://doi. org/10.1038/nature10509)

de Bono JS, Logothetis CJ, Molina A, Fizazi K, North S, Chu L, Chi KN, Jones RJ, Goodman OB, Saad F, et al. 2011 Abiraterone and increased survival in metastatic prostate cancer. New England Journal of Medicine 364 1995-2005. (https://doi.org/10.1056/NEJMoa1014618)

De Mol E, Fenwick RB, Phang CT, Buzón V, Szulc E, De La Fuente A, Escobedo A, García J, Bertoncini CW, Estébanez-Perpiñá E, et al. 2016 EPI-001, A compound active against castration-resistant prostate cancer, targets transactivation unit 5 of the androgen receptor. ACS Chemical Biology 11 2499-2505. (https://doi.org/10.1021/ acschembio.6b00182)

DeLucia DC, Cardillo TM, Ang L, Labrecque MP, Zhang A, Hopkins JE, De Sarkar N, Coleman I, Da Costa RMG, Corey E, et al. 2021 Regulation of CEACAM5 and therapeutic efficacy of an anti-CEACAM5-SN38 antibody-drug conjugate in neuroendocrine prostate cancer. Clinical
Cancer Research 27 759-774. (https://doi.org/10.1158/1078-0432.CCR20-3396)

Dey A, Chitsaz F, Abbasi A, Misteli T \& Ozato K 2003 The double bromodomain protein Brd4 binds to acetylated chromatin during interphase and mitosis. PNAS 100 8758-8763. (https://doi.org/10.1073/ pnas.1433065100)

Dunwoodie SL, Henrique D, Harrison SM \& Beddington RS 1997 Mouse Dll3: a novel divergent Delta gene which may complement the function of other Delta homologues during early pattern formation in the mouse embryo. Development 124 3065-3076.

Ellis P, Fagan BM, Magness ST, Hutton S, Taranova O, Hayashi S, Mcmahon A, Rao M \& Pevny L 2004 SOX2, a persistent marker for multipotential neural stem cells derived from embryonic stem cells, the embryo or the adult. Developmental Neuroscience 26 148-165. (https://doi.org/10.1159/000082134)

Epstein JI, Amin MB, Beltran H, Lotan TL, Mosquera JM, Reuter VE, Robinson BD, Troncoso P \& Rubin MA 2014 Proposed morphologic classification of prostate cancer with neuroendocrine differentiation. American Journal of Surgical Pathology 38 756-767. (https://doi. org/10.1097/PAS.0000000000000208)

Eroglu B, Wang G, Tu N, Sun X \& Mivechi NF 2006 Critical role of Brg1 member of the SWI/SNF chromatin remodeling complex during neurogenesis and neural crest induction in zebrafish. Developmental Dynamics 235 2722-2735. (https://doi.org/10.1002/dvdy.20911)

Etani T, Naiki T, Naiki-Ito A, Suzuki T, Iida K, Nozaki S, Kato H, Nagayasu Y, Suzuki S, Kawai N, et al. 2019 NCL1, A highly selective lysine-specific demethylase 1 inhibitor, suppresses castration-resistant prostate cancer growth via regulation of apoptosis and autophagy. Journal of Clinical Medicine 8 442. (https://doi.org/10.3390/ jcm8040442)

Faber PW, Van Rooij HC, Schipper HJ, Brinkmann AO \& Trapman J 1993 Two different, overlapping pathways of transcription initiation are active on the TATA-less human androgen receptor promoter. The role of Sp1. Journal of Biological Chemistry 268 9296-9301. (https://doi. org/10.1016/S0021-9258(18)98349-3)

Faivre EJ, Wilcox D, Lin X, Hessler P, Torrent M, He W, Uziel T, Albert DH, Mcdaniel K, Kati W, et al. 2017 Exploitation of castration-resistant prostate cancer transcription factor dependencies by the novel BET inhibitor ABBV-075. Molecular Cancer Research 15 35-44. (https://doi. org/10.1158/1541-7786.MCR-16-0221)

Fizazi K, Shore N, Tammela TL, Ulys A, Vjaters E, Polyakov S, Jievaltas M, Luz M, Alekseev B, Kuss I, et al. 2020 Nonmetastatic, castrationresistant prostate cancer and survival with darolutamide. New England Journal of Medicine 383 1040-1049. (https://doi.org/10.1056/ NEJMoa2001342)

Gaddipati JP, Mcleod DG, Heidenberg HB, Sesterhenn IA, Finger MJ, Moul JW \& Srivastava S 1994 Frequent detection of codon 877 mutation in the androgen receptor gene in advanced prostate cancers. Cancer Research $\mathbf{5 4}$ 2861-2864.

Gan Q, Joseph CT, Guo M, Zhang M, Sun X \& Gong Y 2019 Utility of NKX3.1 immunostaining in the detection of metastatic prostatic carcinoma on fine-needle aspiration smears. American Journal of Clinical Pathology 152 495-501. (https://doi.org/10.1093/ajcp/aqz063)

Graham V, Khudyakov J, Ellis P \& Pevny L 2003 SOX2 functions to maintain neural progenitor identity. Neuron 39 749-765. (https://doi. org/10.1016/s0896-6273(03)00497-5)

Han X, Wang C, Qin C, Xiang W, Fernandez-Salas E, Yang CY, Wang M, Zhao L, Xu T, Chinnaswamy K, et al. 2019 Discovery of ARD-69 as a highly potent proteolysis targeting chimera (Protac) degrader of androgen receptor (AR) for the treatment of prostate cancer. Journal of Medicinal Chemistry 62 941-964. (https://doi.org/10.1021/acs.jmedchem.8b01631)

Hirano D, Okada Y, Minei S, Takimoto Y \& Nemoto N 2004 Neuroendocrine differentiation in hormone refractory prostate cancer following androgen deprivation therapy. European Urology 45 586-592; discussion 592. (https://doi.org/10.1016/j.eururo.2003.11.032) https://erc.bioscientifica.com

https://doi.org/10.1530/ERC-21-0002 (c) 2021 Society for Endocrinology Published by Bioscientifica Ltd. Printed in Great Britain 
Hsieh CL, Fei T, Chen Y, Li T, Gao Y, Wang X, Sun T, Sweeney CJ, Lee GS, Chen S, et al. 2014 Enhancer RNAs participate in androgen receptordriven looping that selectively enhances gene activation. PNAS 111 7319-7324. (https://doi.org/10.1073/pnas.1324151111)

Hu R, Dunn TA, Wei S, Isharwal S, Veltri RW, Humphreys E, Han M, Partin AW, Vessella RL, Isaacs WB, et al. 2009 Ligand-independent androgen receptor variants derived from splicing of cryptic exons signify hormone-refractory prostate cancer. Cancer Research 69 16-22. (https://doi.org/10.1158/0008-5472.CAN-08-2764)

Jotatsu T, Yagishita S, Tajima K, Takahashi F, Mogushi K, Hidayat M, Wirawan A, Ko R, Kanemaru R, Shimada N, et al. 2017 LSD1/KDM1 isoform LSD1+8a contributes to neural differentiation in small cell lung cancer. Biochemistry and Biophysics Reports 9 86-94. (https://doi. org/10.1016/j.bbrep.2016.11.015)

Kanan AD, Corey E, Vêncio RZN, Ishwar A \& Liu AY 2019 Lineage relationship between prostate adenocarcinoma and small cell carcinoma. BMC Cancer 19 518. (https://doi.org/10.1186/s12885-0195680-7)

Kibbee-Cram E 1988 Comments from University of Iowa Hospitals and Clinics Burn Center. Journal of Burn Care and Rehabilitation 9 215-216. (https://doi.org/10.1097/00004630-198803000-00021)

Kim J, Lee Y, Lu X, Song B, Fong KW, Cao Q, Licht JD, Zhao JC \& Yu J 2018 Polycomb- and methylation-independent roles of EZH2 as a transcription activator. Cell Reports 25 2808.e4-2820.e4. (https://doi. org/10.1016/j.celrep.2018.11.035)

Kinoshita H, Shi Y, Sandefur C, Meisner LF, Chang C, Choon A, Reznikoff CR, Bova GS, Friedl A \& Jarrard DF 2000 Methylation of the androgen receptor minimal promoter silences transcription in human prostate cancer. Cancer Research 60 3623-3630.

Kleb B, Estecio MR, Zhang J, Tzelepi V, Chung W, Jelinek J, Navone NM, Tahir S, Marquez VE, Issa JP, et al. 2016 Differentially methylated genes and androgen receptor re-expression in small cell prostate carcinomas. Epigenetics 11 184-193. (https://doi.org/10.1080/1559229 4.2016.1146851)

Koivisto P, Kononen J, Palmberg C, Tammela T, Hyytinen E, Isola J, Trapman J, Cleutjens K, Noordzij A, Visakorpi T, et al. 1997 Androgen receptor gene amplification: a possible molecular mechanism for androgen deprivation therapy failure in prostate cancer. Cancer Research 57 314-319.

Kregel S, Kiriluk KJ, Rosen AM, Cai Y, Reyes EE, Otto KB, Tom W, Paner GP, Szmulewitz RZ \& Vander Griend DJ 2013 Sox2 is an androgen receptorrepressed gene that promotes castration-resistant prostate cancer. PLoS ONE 8 e53701. (https://doi.org/10.1371/journal.pone.0053701)

Kregel S, Wang C, Han X, Xiao L, Fernandez-Salas E, Bawa P, Mccollum BL, Wilder-Romans K, Apel IJ, Cao X, et al. 2020 Androgen receptor degraders overcome common resistance mechanisms developed during prostate cancer treatment. Neoplasia 22 111-119. (https://doi. org/10.1016/j.neo.2019.12.003)

Ku SY, Rosario S, Wang Y, Mu P, Seshadri M, Goodrich ZW, Goodrich MM, Labbe DP, Gomez EC, Wang J, et al. 2017 Rb1 and Trp53 cooperate to suppress prostate cancer lineage plasticity, metastasis, and antiandrogen resistance. Science 355 78-83. (https://doi.org/10.1126/ science.aah4199)

Kumar A, Coleman I, Morrissey C, Zhang X, True LD, Gulati R, Etzioni R, Bolouri H, Montgomery B, White T, et al. 2016 Substantial interindividual and limited intraindividual genomic diversity among tumors from men with metastatic prostate cancer. Nature Medicine 22 369-378. (https://doi.org/10.1038/nm.4053)

Kwabi-Addo B, Ozen M \& Ittmann M 2004 The role of fibroblast growth factors and their receptors in prostate cancer. Endocrine-Related Cancer 11 709-724. (https://doi.org/10.1677/erc.1.00535)

Kwon OJ, Zhang L, Jia D \& Xin L 2020a Sox2 is necessary for androgen ablation-induced neuroendocrine differentiation from Pten null Sca1+ prostate luminal cells. Oncogene 40 203-214. (https://doi. org/10.1038/s41388-020-01526-2)
Kwon OJ, Zhang L, Jia D, Zhou Z, Li Z, Haffner M, Lee JK, True L, Morrissey C \& Xin L 2020b De novo induction of lineage plasticity from human prostate luminal epithelial cells by activated AKT1 and c-Myc. Oncogene 39 7142-7151. (https://doi.org/10.1038/s41388-02001487-6)

Labrecque MP, Coleman IM, Brown LG, True LD, Kollath L, Lakely B, Nguyen HM, Yang YC, Da Costa RMG, Kaipainen A, et al. 2019 Molecular profiling stratifies diverse phenotypes of treatmentrefractory metastatic castration-resistant prostate cancer. Journal of Clinical Investigation 129 4492-4505. (https://doi.org/10.1172/ JCI128212)

Laurent B, Ruitu L, Murn J, Hempel K, Ferrao R, Xiang Y, Liu S, Garcia BA, Wu H, Wu F, et al. 2015 A specific LSD1/KDM1A isoform regulates neuronal differentiation through H3K9 demethylation. Molecular Cell 57 957-970. (https://doi.org/10.1016/j. molcel.2015.01.010)

Lee DK, Duan HO \& Chang C 2001 Androgen receptor interacts with the positive elongation factor P-TEFb and enhances the efficiency of transcriptional elongation. Journal of Biological Chemistry 276 9978-9984. (https://doi.org/10.1074/jbc.M002285200)

Lee JK, Phillips JW, Smith BA, Park JW, Stoyanova T, Mccaffrey EF, Baertsch R, Sokolov A, Meyerowitz JG, Mathis C, et al. 2016 N-Myc drives neuroendocrine prostate cancer initiated from human prostate epithelial cells. Cancer Cell 29 536-547. (https://doi.org/10.1016/j. ccell.2016.03.001)

Lee E, Wang J, Jung Y, Cackowski FC \& Taichman RS 2018a Reduction of two histone marks, H3k9me3 and H3k27me3 by epidrug induces neuroendocrine differentiation in prostate cancer. Journal of Cellular Biochemistry 119 3697-3705. (https://doi.org/10.1002/jcb.26586)

Lee JK, Bangayan NJ, Chai T, Smith BA, Pariva TE, Yun S, Vashisht A, Zhang Q, Park JW, Corey E, et al. 2018b Systemic surfaceome profiling identifies target antigens for immune-based therapy in subtypes of advanced prostate cancer. PNAS 115 E4473-E4482. (https://doi. org/10.1073/pnas.1802354115)

Lee GT, Nagaya N, Desantis J, Madura K, Sabaawy HE, Kim WJ, Vaz RJ, Cruciani G \& Kim IY 2021 Effects of MTX-23, a novel protac of androgen receptor splice variant-7 and androgen receptor, on CRPC resistant to second-line antiandrogen therapy. Molecular Cancer Therapeutics 20 490499. (https://doi.org/10.1158/1535-7163.MCT-20-0417)

Lessard J, Wu JI, Ranish JA, Wan M, Winslow MM, Staahl BT, Wu H, Aebersold R, Graef IA \& Crabtree GR 2007 An essential switch in subunit composition of a chromatin remodeling complex during neural development. Neuron 55 201-215. (https://doi.org/10.1016/j. neuron.2007.06.019)

Li Y, Hwang TH, Oseth LA, Hauge A, Vessella RL, Schmechel SC, Hirsch B, Beckman KB, Silverstein KA \& Dehm SM 2012 AR intragenic deletions linked to androgen receptor splice variant expression and activity in models of prostate cancer progression. Oncogene 31 4759-4767. (https://doi.org/10.1038/onc.2011.637)

Li Y, Donmez N, Sahinalp C, Xie N, Wang Y, Xue H, Mo F, Beltran H, Gleave M, Wang Y, et al. 2017 SRRM4 drives neuroendocrine transdifferentiation of prostate adenocarcinoma under androgen receptor pathway inhibition. European Urology 71 68-78. (https://doi. org/10.1016/j.eururo.2016.04.028)

Li Y, Zhang Q, Lovnicki J, Chen R, Fazli L, Wang Y, Gleave M, Huang J \& Dong X 2019 SRRM4 gene expression correlates with neuroendocrine prostate cancer. Prostate 79 96-104. (https://doi.org/10.1002/ pros.23715)

Li H, Wang L, Li Z, Geng X, Li M, Tang Q, Wu C \& Lu Z 2020a SOX2 has dual functions as a regulator in the progression of neuroendocrine prostate cancer. Laboratory Investigation 100 570-582. (https://doi. org/10.1038/s41374-019-0343-5)

Li Y, Yang R, Henzler CM, Ho Y, Passow C, Auch B, Carreira S, Nava Rodrigues D, Bertan C, Hwang TH, et al. 2020b Diverse AR gene rearrangements mediate resistance to androgen receptor inhibitors in https://erc.bioscientifica.com https://doi.org/10.1530/ERC-21-0002 (c) 2021 Society for Endocrinology Published by Bioscientifica Ltd. Printed in Great Britain 
metastatic prostate cancer. Clinical Cancer Research 26 1965-1976. (https://doi.org/10.1158/1078-0432.CCR-19-3023)

Lindzey J, Grossmann M, Kumar MV \& Tindall DJ 1993 Regulation of the 5 '-flanking region of the mouse androgen receptor gene by cAMP and androgen. Molecular Endocrinology 7 1530-1540. (https://doi. org/10.1210/mend.7.12.7511785)

Liu Q, Wang G, Li Q, Jiang W, Kim JS, Wang R, Zhu S, Wang X, Yan L, Yi Y, et al. 2019a Polycomb group proteins EZH2 and EED directly regulate androgen receptor in advanced prostate cancer. International Journal of Cancer 145 415-426. (https://doi.org/10.1002/ijc.32118)

Liu Y, Horn JL, Banda K, Goodman AZ, Lim Y, Jana S, Arora S, Germanos AA, Wen L, Hardin WR, et al. 2019b The androgen receptor regulates a druggable translational regulon in advanced prostate cancer. Science Translational Medicine 11 eaaw4993. (https://doi. org/10.1126/scitranslmed.aaw4993)

McAuley E, Moline D, Vanopstall C, Lamperis S, Brown R \& Vander Griend DJ 2019 Sox 2 expression marks castration-resistant progenitor cells in the adult murine prostate. Stem Cells 37 690-700. (https://doi. org/10.1002/stem.2987)

Metz EP, Wilder PJ, Dong J, Datta K \& Rizzino A 2020 Elevating SOX2 in prostate tumor cells upregulates expression of neuroendocrine genes, but does not reduce the inhibitory effects of enzalutamide. Journal of Cellular Physiology 235 3731-3740. (https://doi.org/10.1002/jcp.29267)

Miyagi S, Saito T, Mizutani K, Masuyama N, Gotoh Y, Iwama A, Nakauchi H, Masui S, Niwa H, Nishimoto M, et al. 2004 The Sox-2 regulatory regions display their activities in two distinct types of multipotent stem cells. Molecular and Cellular Biology 24 4207-4220. (https://doi.org/10.1128/mcb.24.10.4207-4220.2004)

Mizokami A, Yeh SY \& Chang C 1994 Identification of 3',5'-cyclic adenosine monophosphate response element and other cis-acting elements in the human androgen receptor gene promoter. Molecular Endocrinology 8 77-88. (https://doi.org/10.1210/mend.8.1.8152432)

Montgomery RB, Mostaghel EA, Vessella R, Hess DL, Kalhorn TF, Higano CS, True LD \& Nelson PS 2008 Maintenance of intratumoral androgens in metastatic prostate cancer: a mechanism for castrationresistant tumor growth. Cancer Research 68 4447-4454. (https://doi. org/10.1158/0008-5472.CAN-08-0249)

Moreno N, Holsten T, Mertins J, Zhogbi A, Johann P, Kool M, Meisterernst M \& Kerl K 2017 Combined BRD4 and CDK9 inhibition as a new therapeutic approach in malignant rhabdoid tumors. Oncotarget 8 84986-84995. (https://doi.org/10.18632/ oncotarget.18583)

Mu P, Zhang Z, Benelli M, Karthaus WR, Hoover E, Chen CC, Wongvipat J, Ku SY, Gao D, Cao Z, et al. 2017 SOX2 promotes lineage plasticity and antiandrogen resistance in TP53- and RB1-deficient prostate cancer. Science 355 84-88. (https://doi.org/10.1126/science.aah4307)

Myung JK, Banuelos CA, Fernandez JG, Mawji NR, Wang J, Tien AH, Yang YC, Tavakoli I, Haile S, Watt K, et al. 2013 An androgen receptor N-terminal domain antagonist for treating prostate cancer. Journal of Clinical Investigation 123 2948-2960. (https://doi.org/10.1172/ JCI66398)

Nakano Y, Wiechert S \& Bánfi B 2019 Overlapping activities of two neuronal splicing factors switch the GABA effect from excitatory to inhibitory by regulating REST. Cell Reports 27 860.e8-871.e8. (https:// doi.org/10.1016/j.celrep.2019.03.072)

Newmark JR, Hardy DO, Tonb DC, Carter BS, Epstein JI, Isaacs WB, Brown TR \& Barrack ER 1992 Androgen receptor gene mutations in human prostate cancer. PNAS 89 6319-6323. (https://doi.org/10.1073/ pnas.89.14.6319)

Nouri M, Massah S, Caradec J, Lubik AA, Li N, Truong S, Lee AR, Fazli L, Ramnarine VR, Lovnicki JM, et al. 2020 Transient Sox9 expression facilitates resistance to androgen-targeted therapy in prostate cancer. Clinical Cancer Research 26 1678-1689. (https://doi.org/10.1158/10780432.CCR-19-0098)

Nyquist MD, Corella A, Coleman I, De Sarkar N, Kaipainen A, Ha G, Gulati R, Ang L, Chatterjee P, Lucas J, et al. 2020 Combined TP53 and
RB1 loss promotes prostate cancer resistance to a spectrum of therapeutics and confers vulnerability to replication stress. Cell Reports 31 107669. (https://doi.org/10.1016/j.celrep.2020.107669)

Olave I, Wang W, Xue Y, Kuo A \& Crabtree GR 2002 Identification of a polymorphic, neuron-specific chromatin remodeling complex. Genes and Development 16 2509-2517. (https://doi.org/10.1101/gad.992102)

Orellana ME, Belfort R, Antecka E \& Burnier MN 2016 Immunohistochemical analysis of retinoblastoma cell phenotype using neuronal and glial cell markers. Arquivos Brasileiros de Oftalmologia 79 395-399. (https://doi.org/10.5935/00042749.20160111)

Parwani AV, Kronz JD, Genega EM, Gaudin P, Chang S \& Epstein JI 2004 Prostate carcinoma with squamous differentiation: an analysis of 33 cases. American Journal of Surgical Pathology 28 651-657. (https://doi. org/10.1097/00000478-200405000-00014)

Pawar A, Gollavilli PN, Wang S \& Asangani IA 2018 Resistance to BET inhibitor leads to alternative therapeutic vulnerabilities in castrationresistant prostate cancer. Cell Reports 22 2236-2245. (https://doi. org/10.1016/j.celrep.2018.02.011)

Peterlin BM \& Price DH 2006 Controlling the elongation phase of transcription with P-TEFb. Molecular Cell 23 297-305. (https://doi. org/10.1016/j.molcel.2006.06.014)

Puca L, Gavyert K, Sailer V, Conteduca V, Dardenne E, Sigouros M, Isse K, Kearney M, Vosoughi A, Fernandez L, et al. 2019 Delta-like protein 3 expression and therapeutic targeting in neuroendocrine prostate cancer. Science Translational Medicine 11 eav0891. (https://doi. org/10.1126/scitranslmed.aav0891)

Puissant A, Frumm SM, Alexe G, Bassil CF, Qi J, Chanthery YH, Nekritz EA, Zeid R, Gustafson WC, Greninger P, et al. 2013 Targeting MYCN in neuroblastoma by BET bromodomain inhibition. Cancer Discovery 3 308-323. (https://doi.org/10.1158/2159-8290.CD-12-0418)

Quigley DA, Dang HX, Zhao SG, Lloyd P, Aggarwal R, Alumkal JJ, Foye A, Kothari V, Perry MD, Bailey AM, et al. 2018 Genomic hallmarks and structural variation in metastatic prostate. Cancer. Cell 174 758.e9769.e9. (https://doi.org/10.1016/j.cell.2018.06.039)

Raina K, Lu J, Qian Y, Altieri M, Gordon D, Rossi AM, Wang J, Chen X, Dong H, Siu K, et al. 2016 Protac-induced BET protein degradation as a therapy for castration-resistant prostate cancer. PNAS 113 7124-7129. (https://doi.org/10.1073/pnas.1521738113)

Raj B, O’Hanlon D, Vessey JP, Pan Q, Ray D, Buckley NJ, Miller FD \& Blencowe BJ 2011 Cross-regulation between an alternative splicing activator and a transcription repressor controls neurogenesis. Molecular Cell 43 843-850. (https://doi.org/10.1016/j. molcel.2011.08.014)

Reebye V, Querol Cano L, Lavery DN, Brooke GN, Powell SM, Chotai D, Walker MM, Whitaker HC, Wait R, Hurst HC, et al. 2012 Role of the HSP90-associated cochaperone p23 in enhancing activity of the androgen receptor and significance for prostate cancer. Molecular Endocrinology 26 1694-1706. (https://doi.org/10.1210/me.2012-1056)

Salami J, Alabi S, Willard RR, Vitale NJ, Wang J, Dong H, Jin M, Mcdonnell DP, Crew AP, Neklesa TK, et al. 2018 Androgen receptor degradation by the proteolysis-targeting chimera ARCC-4 outperforms enzalutamide in cellular models of prostate cancer drug resistance. Communications Biology 1 100. (https://doi.org/10.1038/s42003-0180105-8)

Scher HI, Fizazi K, Saad F, Taplin ME, Sternberg CN, Miller K, De Wit R, Mulders P, Chi KN, Shore ND, et al. 2012 Increased survival with enzalutamide in prostate cancer after chemotherapy. New England Journal of Medicine 367 1187-1197. (https://doi.org/10.1056/ NEJMoa1207506)

Scher HI, Graf RP, Schreiber NA, Mclaughlin B, Jendrisak A, Wang Y, Lee J, Greene S, Krupa R, Lu D, et al. 2017 Phenotypic heterogeneity of circulating tumor cells informs clinical decisions between AR signaling inhibitors and taxanes in metastatic prostate cancer. Cancer Research 77 5687-5698. (https://doi.org/10.1158/0008-5472.CAN-171353) https://erc.bioscientifica.com

https://doi.org/10.1530/ERC-21-0002 (c) 2021 Society for Endocrinology Published by Bioscientifica Ltd. Printed in Great Britain 
Sehrawat A, Gao L, Wang Y, Bankhead A, Mcweeney SK, King CJ, Schwartzman J, Urrutia J, Bisson WH, Coleman DJ, et al. 2018 LSD1 activates a lethal prostate cancer gene network independently of its demethylase function. PNAS 115 E4179-E4188. (https://doi. org/10.1073/pnas.1719168115)

Seo S, Richardson GA \& Kroll KL 2005 The SWI/SNF chromatin remodeling protein Brg1 is required for vertebrate neurogenesis and mediates transactivation of Ngn and NeuroD. Development 132 105-115. (https://doi.org/10.1242/dev.01548)

Shahbazi J, Liu PY, Atmadibrata B, Bradner JE, Marshall GM, Lock RB \& Liu T 2016 The bromodomain inhibitor JQ1 and the histone deacetylase inhibitor panobinostat synergistically reduce N-Myc expression and induce anticancer effects. Clinical Cancer Research 22 2534-2544. (https://doi.org/10.1158/1078-0432.CCR-15-1666)

Sharma A, Yeow WS, Ertel A, Coleman I, Clegg N, Thangavel C, Morrissey C, Zhang X, Comstock CE, Witkiewicz AK, et al. 2010 The retinoblastoma tumor suppressor controls androgen signaling and human prostate cancer progression. Journal of Clinical Investigation 120 4478-4492. (https://doi.org/10.1172/JCI44239)

Sharp A, Coleman I, Yuan W, Sprenger C, Dolling D, Rodrigues DN, Russo JW, Figueiredo I, Bertan C, Seed G, et al. 2019 Androgen receptor splice variant-7 expression emerges with castration resistance in prostate cancer. Journal of Clinical Investigation 129 192-208. (https:// doi.org/10.1172/JCI122819)

Smith MR, Saad F, Chowdhury S, Oudard S, Hadaschik BA, Graff JN Olmos D, Mainwaring PN, Lee JY, Uemura H, et al. 2021 Apalutamide and overall survival in prostate cancer. European Urology 79 150-158. (https://doi.org/10.1016/j.eururo.2020.08.011)

Sutter R, Shakhova O, Bhagat H, Behesti H, Sutter C, Penkar S, Santuccione A, Bernays R, Heppner FL, Schüller U, et al. 2010 Cerebellar stem cells act as medulloblastoma-initiating cells in a mouse model and a neural stem cell signature characterizes a subset of human medulloblastomas. Oncogene 29 1845-1856. (https://doi. org/10.1038/onc.2009.472)

Suzuki K, Terakawa T, Jimbo N, Inaba R, Nakano Y \& Fujisawa M 2020 Clinical features of treatment-related neuroendocrine prostate cancer: a case series. Anticancer Research 40 3519-3526. (https://doi. org/10.21873/anticanres.14340)

Takeda DY, Spisák S, Seo JH, Bell C, O’Connor E, Korthauer K, Ribli D, Csabai I, Solymosi N, Szállási Z, et al. 2018 A somatically acquired enhancer of the androgen receptor is a noncoding driver in advanced prostate. Cancer. Cell 174 422.e13-432.e13. (https://doi.org/10.1016/j. cell.2018.05.037)

Takwale AD, Jo SH, Jeon YU, Kim HS, Shin CH, Lee HK, Ahn S, Lee CO, Du Ha J, Kim JH, et al. 2020 Design and characterization of cereblonmediated androgen receptor proteolysis-targeting chimeras. European Journal of Medicinal Chemistry 208 112769. (https://doi.org/10.1016/j. ejmech.2020.112769)

Tang J, Yoo AS \& Crabtree GR 2013 Reprogramming human fibroblasts to neurons by recapitulating an essential microRNA-chromatin switch. Current Opinion in Genetics and Development 23 591-598. (https://doi. org/10.1016/j.gde.2013.07.001)

Tilley WD, Marcelli M \& Mcphaul MJ 1990 Expression of the human androgen receptor gene utilizes a common promoter in diverse human tissues and cell lines. Journal of Biological Chemistry 265 13776-13781. (https://doi.org/10.1016/S0021-9258(18)77416-4)

Tong B, Zeng J, Wu Y \& Xiong W 2015 Enhanced SOX2 expression in retinoblastoma tissues and peripheral blood is associated with the clinicopathological characteristics of the disease. Oncology Letters 9 1244-1248. (https://doi.org/10.3892/ol.2015.2857)
Tran C, Ouk S, Clegg NJ, Chen Y, Watson PA, Arora V, Wongvipat J, SmithJones PM, Yoo D, Kwon A, et al. 2009 Development of a secondgeneration antiandrogen for treatment of advanced prostate cancer. Science 324 787-790. (https://doi.org/10.1126/science.1168175)

Tsai HK, Lehrer J, Alshalalfa M, Erho N, Davicioni E \& Lotan TL 2017 Gene expression signatures of neuroendocrine prostate cancer and primary small cell prostatic carcinoma. BMC Cancer 17 759. (https://doi. org/10.1186/s12885-017-3729-z)

Uwanogho D, Rex M, Cartwright EJ, Pearl G, Healy C, Scotting PJ \& Sharpe PT 1995 Embryonic expression of the chicken Sox2, Sox3 and Sox11 genes suggests an interactive role in neuronal development. Mechanisms of Development 49 23-36. (https://doi.org/10.1016/09254773(94)00299-3)

Vogel-Ciernia A, Matheos DP, Barrett RM, Kramár EA, Azzawi S, Chen Y, Magnan CN, Zeller M, Sylvain A, Haettig J, et al. 2013 The neuronspecific chromatin regulatory subunit BAF53b is necessary for synaptic plasticity and memory. Nature Neuroscience 16 552-561. (https://doi. org/10.1038/nn.3359)

Vollmuth F, Blankenfeldt W \& Geyer M 2009 Structures of the dual bromodomains of the P-TEFb-activating protein Brd4 at atomic resolution. Journal of Biological Chemistry 284 36547-36556. (https:// doi.org/10.1074/jbc.M109.033712)

Walter GF \& Ratzenhofer M 1979 Disseminated endocrine cells of the gastrointestinal tract and their possible influence on gastrointestinal disease. Israel Journal of Medical Sciences 15 374-381.

Welti J, Sharp A, Yuan W, Dolling D, Nava Rodrigues D, Figueiredo I, Gil V, Neeb A, Clarke M, Seed G, et al. 2018 Targeting bromodomain and extra-terminal (BET) family proteins in castration-resistant prostate cancer (CRPC). Clinical Cancer Research 24 3149-3162. (https://doi. org/10.1158/1078-0432.CCR-17-3571)

Xiang Q, Zhang Y, Li J, Xue X, Wang C, Song M, Zhang C, Wang R, Li C, Wu C, et al. 2018 Y08060: a selective BET inhibitor for treatment of prostate cancer. ACS Medicinal Chemistry Letters 9 262-267. (https:// doi.org/10.1021/acsmedchemlett.8b00003)

Xu K, Wu ZJ, Groner AC, He HH, Cai C, Lis RT, Wu X, Stack EC, Loda M, Liu T, et al. 2012 EZH2 oncogenic activity in castration-resistant prostate cancer cells is Polycomb-independent. Science 338 1465-1469. (https://doi.org/10.1126/science.1227604)

Yoo AS, Staahl BT, Chen L \& Crabtree GR 2009 MicroRNA-mediated switching of chromatin-remodelling complexes in neural development. Nature 460 642-646. (https://doi.org/10.1038/ nature08139)

Yu X, Cates JM, Morrissey C, You C, Grabowska MM, Zhang J, Degraff DJ, Strand DW, Franco OE, Lin-Tsai O, et al. 2014 SOX2 expression in the developing, adult, as well as, diseased prostate. Prostate Cancer and Prostatic Diseases 17 301-309. (https://doi.org/10.1038/pcan.2014.29)

Zhang X, Morrissey C, Sun S, Ketchandji M, Nelson PS, True LD, VakarLopez F, Vessella RL \& Plymate SR 2011 Androgen receptor variants occur frequently in castration resistant prostate cancer metastases. PLoS ONE 6 e27970. (https://doi.org/10.1371/journal.pone.0027970)

Zhang X, Coleman IM, Brown LG, True LD, Kollath L, Lucas JM, Lam HM, Dumpit R, Corey E, Chery L, et al. 2015 SRRM4 expression and the loss of REST activity may promote the emergence of the neuroendocrine phenotype in castration-resistant prostate cancer. Clinical Cancer Research 21 4698-4708. (https://doi.org/10.1158/1078-0432.CCR-15-0157)

Zou M, Toivanen R, Mitrofanova A, Floch N, Hayati S, Sun Y, Le Magnen C, Chester D, Mostaghel EA, Califano A, et al. 2017 Transdifferentiation as a mechanism of treatment resistance in a mouse model of castration-resistant prostate cancer. Cancer Discovery 7 736-749. (https://doi.org/10.1158/2159-8290.CD-16-1174)

Received in final form 26 February 2021

Accepted 31 March 2021

Accepted Manuscript published online 1 April 2021 https://erc bioscientifica com https://doi.org/10.1530/ERC-21-0002 (c) 2021 Society for Endocrinology Published by Bioscientifica Ltd. Printed in Great Britain 